\title{
Geniposide inhibits non-small cell lung cancer cell migration and angiogenesis by regulating PPAR $\gamma /$ VEGF-A pathway
}

\author{
Ming Jiang ${ }^{1,2}$, Shiying Zheng ${ }^{1 *}$ \\ ${ }^{1}$ Department of Cardiothoracic Surgery, The First Affiliated Hospital of Soochow University, Suzhou, Jiangsu Province, \\ China; ${ }^{2}$ Department of Thoracic Surgery, Gaoyou People's Hospital, Yangzhou, Jiangsu Province, China
}

*Corresponding Author: Shiying Zheng, Department of Cardiothoracic Surgery, First Affiliated Hospital of Soochow University, No. 188, Shizi Street, Suzhou City, Jiangsu Province 215006, China. Email: zhengsiying11126@163.com

Received: 26 November 2021; Accepted: 6 December 2021; Published: 21 January 2022

(C) 2022 Codon Publications

OPEN ACCESS @C) ORIGINAL ARTICLE

\begin{abstract}
Geniposide, an iridoid glycoside derived from traditional Chinese herb, Gardenia jasminoides Ellis, exerts antitumor effect against distinct cancers. The role of geniposide in the migration and angiogenesis of non-small cell lung cancer (NSCLC) cell was investigated in this study. Cancer cells were incubated with various concentrations of geniposide, and proliferative ability was detected by Cell Counting Kit-8 (CCK-8) and 5-ethynyl-2'-deoxyuridine (EdU) staining. Wound healing and transwell were used to assess cell migration and invasion, respectively. Tube formation assay was performed to investigate angiogenesis. Geniposide reduced NSCLC cell proliferation, and suppressed NSCLC cell migration and invasion in a dosage-dependent manner. Angiogenesis of NSCLC was also inhibited by geniposide. Geniposide increased the protein expression of peroxisome proliferator-activated receptor gamma (PPAR $\gamma$ ) and decreased vascular endothelial growth factor-A (VEGF-A) protein expression in NSCLC cells. Incubation with a PPAR $\gamma$ antagonist, GW9662, attenuated geniposide-induced up-regulation of PPAR $\gamma$ and down-regulation of VEGF-A. Over-expression of VEGF-A weakened geniposide-suppressed cell proliferation, migration, and angiogenesis of NSCLC. Geniposide exerted antitumor and anti-angiogenic actions on NSCLC through regulation of PPAR $\gamma /$ VEGF-A pathway.
\end{abstract}

Keywords: geniposide; migration; angiogenesis; non-small cell lung cancer; PPARү; VEGF-A

\section{Introduction}

Lung cancer, a common cause of cancer-related mortality, is one of the most prevalent malignancies (Thawani et al., 2020). Non-small cell lung cancer (NSCLC), with high morbidity and mortality, contributes to more than $80 \%$ of the diagnosed lung-cancer cases (Gridelli et al., 2015). Therapeutic strategies, such as surgery, radiotherapy, chemotherapy, and molecular-targeted therapy, are commonly used in the treatment of early-stage NSCLC (Loong et al., 2018). However, these strategies demonstrate less beneficial effects on patients having advancedstage NSCLC because of high risk of recurrence (Kim et al., 2013). The 5-year survival rate of patients with advanced-stage NSCLC is less than 10\% (Garon et al., 2019).

NSCLC cell migration and invasion have been demonstrated to be associated with the poor prognosis and lung-cancer mortality (Yang et al., 2016). Moreover, angiogenesis is characterized by the abnormal proliferation and migration of vascular endothelial cells in response to the metabolic demand of tumor cells, and contributes to the metastasis and recurrence of NSCLC (D’Amico, 2004). Targeting angiogenesis of vascular endothelial cells is considered as a promising strategy 
for the treatment of NSCLC (Malapelle and Rossi, 2019). Vascular endothelial growth factor (VEGF) is the prime mediator of vascular endothelial cell proliferation and migration, contributing to the progression of NSCLC; inhibition of VEGF suppressed cancer growth and metastasis (Keedy and Sandler, 2007).

Geniposide is an iridoid glycoside derived from traditional Chinese herb, Gardenia jasminoides Ellis, and is widely known as an anti-inflammatory, antioxidant, and antitumor agent (Lichota and Gwozdzinski, 2018; Liu et al., 2009, et al.2013). For example, geniposide inhibited the proliferation of diffused large B-cell lymphoma $(\mathrm{Hu}$ et al., 2020), and suppressed gastric cancer cell migration and invasion (Ma and Ding, 2018), and promoted the apoptosis of oral squamous cell carcinoma cell (Cheng et al., 2017). Geniposide also inhibited the secretion of VEGF in hepatocellular carcinoma, and suppressed the migration and angiogenesis of endothelial cells (Zhang et al., 2020). However, there are few studies considering the role of geniposide in NSCLC, and the relevant mechanism is still unclear.

The effects of geniposide on NSCLC cell proliferation and metastasis as well as its role in angiogenesis were investigated in this study. The underling mechanism involved in geniposide-inhibited tumor migration and angiogenesis could provide a promising strategy for NSCLC.

\section{Materials and Methods}

\section{Cell culture and treatment}

Lung cancer cells (A549 and NCI-H1299; American Type Culture Collection, Manassas, VA, USA) were cultured in Dulbecco's modified Eagle's medium (Invitrogen, Carlsbad, CA, USA) supplemented with $10 \%$ fetal bovine serum and penicillin-streptomycin (Invitrogen). Cells were incubated with 100-, 200-, 300-, or 400- $\mu \mathrm{M}$ geniposide (Sigma-Aldrich, San Francisco, CA, USA) according to a previous study (Yu et al., 2020), or co-incubated with 300- $\mu \mathrm{M}$ geniposide and 10- $\mathrm{MM}$ GW9662 (SigmaAldrich) for $24 \mathrm{~h}$. Cells were transfected with plasmid cloning DNA (pcDNA) vector or pcDNA-VEGF-A (Genepharma, Suzhou, China) for 48 h before incubation with geniposide or GW9662.

\section{Cell viability and proliferation assays}

A549 and NCI-H1299 cells with indicated incubation and transfection were seeded in 96-well plates for 24, 48, or $72 \mathrm{~h}$. Cells were then incubated with $10-\mu \mathrm{L}$ cell counting kit-8 (CCK-8) reagent (Beyotime, Beijing, China) for another $2 \mathrm{~h}$. Absorbance at $450 \mathrm{~nm}$ was detected by a microplate reader (Thermo Fisher Scientific, Waltham, MA, USA) according to the study conducted by Yu et al. (2020). For cell proliferation assay, cells were seeded in 48-well plates, and $200 \mu \mathrm{L}$ of 5-ethynyl-2'-deoxyuridine (EdU; Beyotime) was added in each well and incubated for $2 \mathrm{~h}$ according to the study conducted by Chen et al. (2021). Cells were then fixed with $4 \%$ paraformaldehyde, permeabilized with $0.5 \%$ Triton X-100, and incubated with Apollo Staining reaction liquid. Cells were measured under Olympus ZKX53 microscope (Olympus, Tokyo, Japan) followed by counterstaining with DAPI (Sigma-Aldrich).

\section{Cell migration and invasion assays}

A549 and NCI-H1299 cells with indicated incubation and transfection were seeded in 6-well plates for $24 \mathrm{~h}$ according to a previous study (Elkhider et al., 2020). A $200-\mu \mathrm{L}$ pipette tip was used to generate scratch in the middle of each well. The wound was observed under the microscope after $24 \mathrm{~h}$, and the wound width was calculated by Image J (v.1.46; National Institutes of Health, Bethesda, MD, USA). For cell invasion assay, cells in serum-free medium were plated into the upper chambers of Transwell chambers (Corning Incorporated, Corning, NY, USA), and medium with 15\% fetal bovine serum was planted into the lower chambers according to the study conducted by Elkhider et al. (2020). Cells in the upper chamber were removed after $24 \mathrm{~h}$, and cells in the lower chamber were stained with crystal violet. Cells were observed under the stated microscope (Olympus).

\section{Tube formation assay}

Human umbilical vein endothelial cells (HUVECs) with conditioned medium (Invitrogen) were seeded in 24-well plates precoated with basement membrane matrix containing reduced growth factor (Invitrogen) according to a previous study (Wang et al., 2021). The culture medium of A549 and NCI-H1299 cells with indicated incubation and transfection was added into each well, and incubated for $6 \mathrm{~h}$. Cells were then washed and fixed with $4 \%$ paraformaldehyde. The figures of tube formation were observed under the stated microscope, and the number of tubes was calculated by ImageJ.

\section{Western blot assay}

A549 and NCI-H1299 cells were lysed in radioimmunoprecipitation assay (RIPA) buffer (Beyotime), and the protein samples were separated by $10 \%$ sodium dodecyl sulfate-polyacrylamide gel electrophoresis (SDS-PAGE), and transferred onto nitrocellulose membranes. The 
membranes were blocked in 5\% bovine serum albumin and probed with specific antibodies: anti-peroxisome proliferator-activated receptor gamma (PPAR $\gamma, 1: 2,500$; Abcam), anti-VEGF-A (1:3,500; Abcam), and anti-glyceraldehyde 3-phosphate dehydrogenase (GAPDH, 1:4,500; Abcam). The membranes were then washed and incubated with horseradish peroxidase-conjugated secondary antibody (1:5,000; Abcam) and tetramethylbenzidine. The immunoreactivities were visualized using enhanced chemiluminescence (Sigma-Aldrich).

\section{Statistical analysis}

The data with at least triple replicates were expressed as mean \pm standard error of mean (SEM), and analyzed by
Student's $t$-test or one-way analysis of variance (ANOVA) with Tukey's post-hoc test using the SPSS software. $P<$ 0.05 was considered as statistically significant.

\section{Results}

\section{Geniposide repressed NSCLC cell proliferation}

In order to investigate the role of geniposide in the progression of NSCLC, NSCLC cell lines (A549 and NCIH1299) were treated with different concentrations of geniposide. Incubation with geniposide reduced the viabilities of A549 and NCI-H1299 cells in a dosage-dependent manner (Figure 1A). The viabilities of A549 and NCI-H1299 cells were reduced by almost $50 \%$ followed

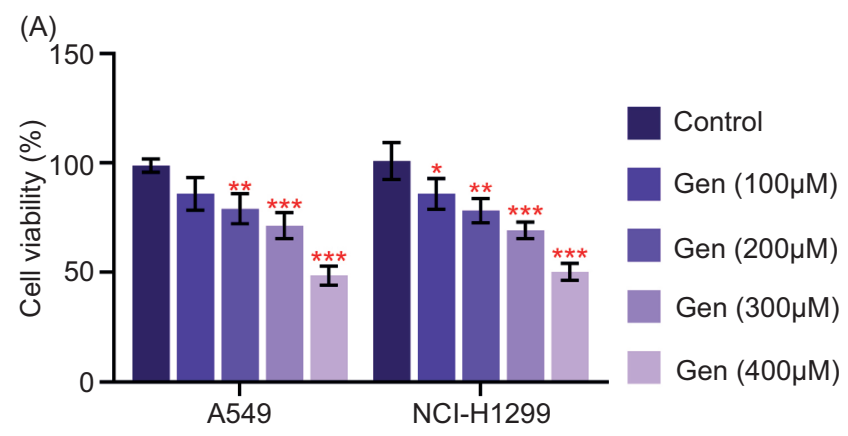

(B)
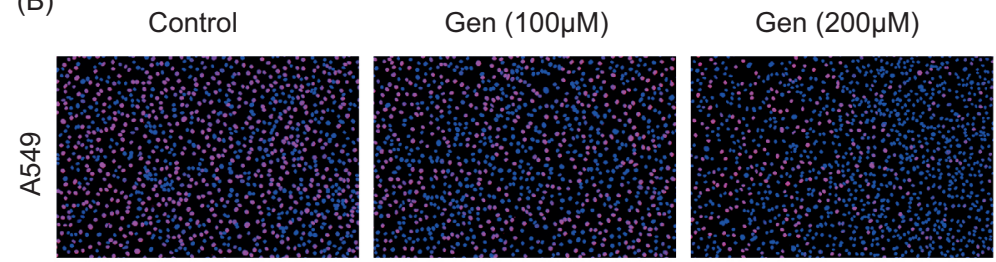

Gen $(300 \mu \mathrm{M})$
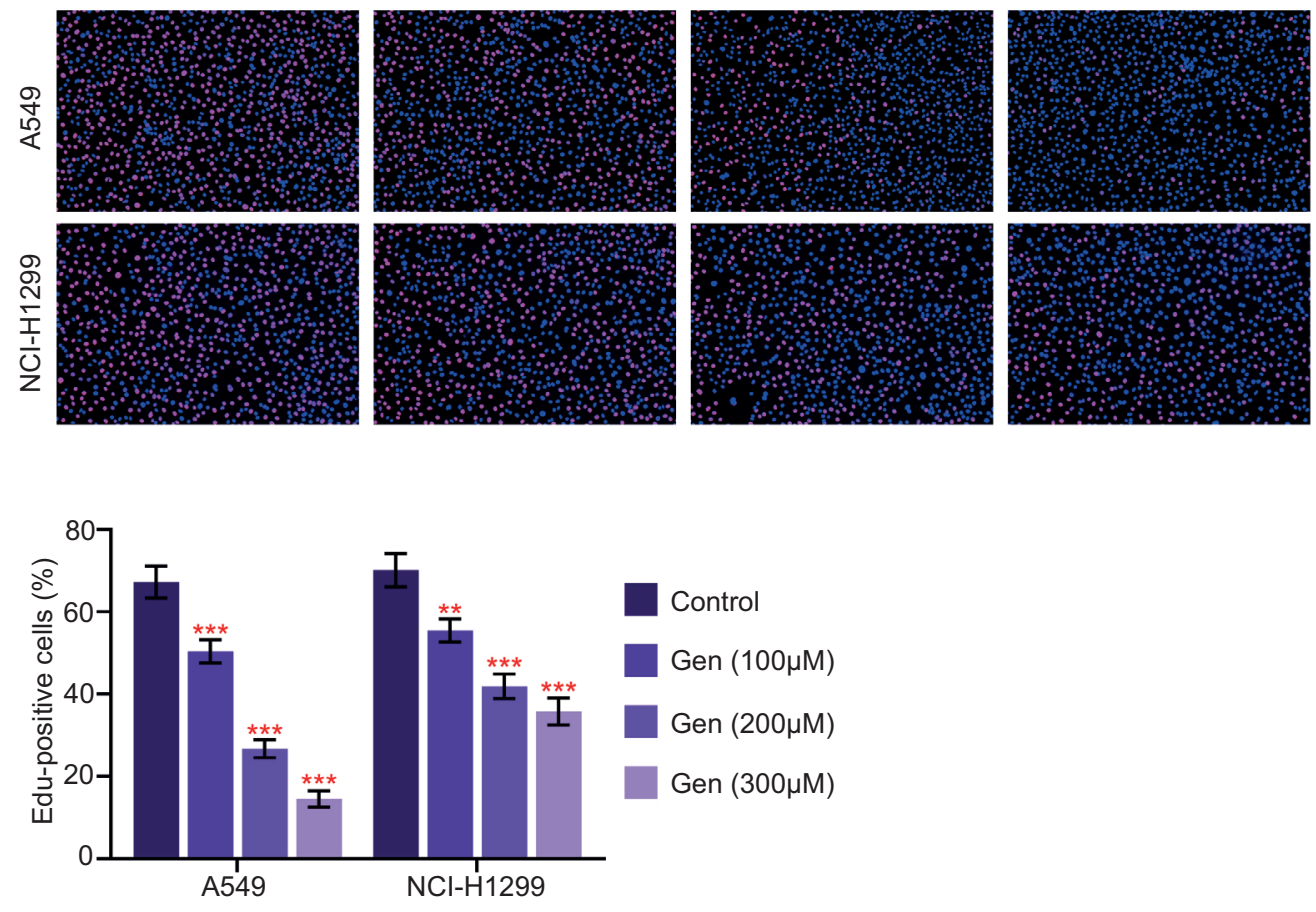

Figure 1. Geniposide repressed NSCLC cell proliferation. (A) Incubation with geniposide reduced the viability of A549 and $\mathrm{NCl}-\mathrm{H} 1299$ cells in a dosage-dependent manner. (B) Incubation with geniposide reduced the number of EdU positive A549 and $\mathrm{NCl}-\mathrm{H} 1299$ cells in a dosage-dependent manner. ${ }^{*} P<0.05,{ }^{* *} P<0.01,{ }^{* *} P<0.001$. 
by $400-\mu \mathrm{M}$ geniposide incubation (Figure 1A). Moreover, geniposide reduced the number of EdU positive A549 and NCI-H1299 cells in a dosage-dependent manner (Figure 1B), suggesting its antiproliferative effect against NSCLC.

\section{Geniposide repressed NSCLC cell migration and invasion}

Wound healing assay demonstrated that the wound width of A549 and NCI-H1299 cells was reduced by geniposide treatment (Figure 2A). The invasive number of A549 and NCI-H1299 cells was also reduced by geniposide treatment (Figure 2B), demonstrating the anti-migrative effect of geniposide against NSCLC.

\section{Geniposide repressed angiogenesis of NSCLC}

Human umbilical vein endothelial cells were treated with the supernatant of A549 and NCI-H1299 post-incubation with different concentrations of geniposide. The tube formation assay indicated that incubation with geniposide reduced the number of tubes (Figure 3), thus revealing its anti-angiogenic effect against NSCLC.

\section{Geniposide reduced the expression of VEGF-A through activation of PPAR $\gamma$}

The protein expression of PPAR $\gamma$ was up-regulated, while VEGF-A was down-regulated in A549 and NCIH1299 cells by geniposide treatment in a dosage-dependent manner (Figure 4A). A549 and NCI-H1299 cells were then co-treated with GW9662 and geniposide. Incubation with a potent antagonist of PPAR $\gamma, \mathrm{GW} 9662$, attenuated geniposide-induced up-regulation of PPAR $\gamma$ and down-regulation of VEGF-A (Figure 4B), indicating that geniposide reduced VEGF-A in NSCLC through up-regulation of PPAR $\gamma$.

\section{Geniposide repressed NSCLC cell migration and angio- genesis through regulation of VEGF-A}

In order to investigate the role of geniposide/VEGF-A in NSCLC, A549 cell was transfected with pcDNAVEGF-A and incubated with $300 \mu \mathrm{M}$ of geniposide. Over-expression of VEGF-A increased the viability of geniposide-induced A549 cell (Figure 5A). The suppressed A549 cell migration (Figure 5B) and invasion (Figures $5 \mathrm{C}$ and $\mathrm{D}$ ) driven by geniposide were also
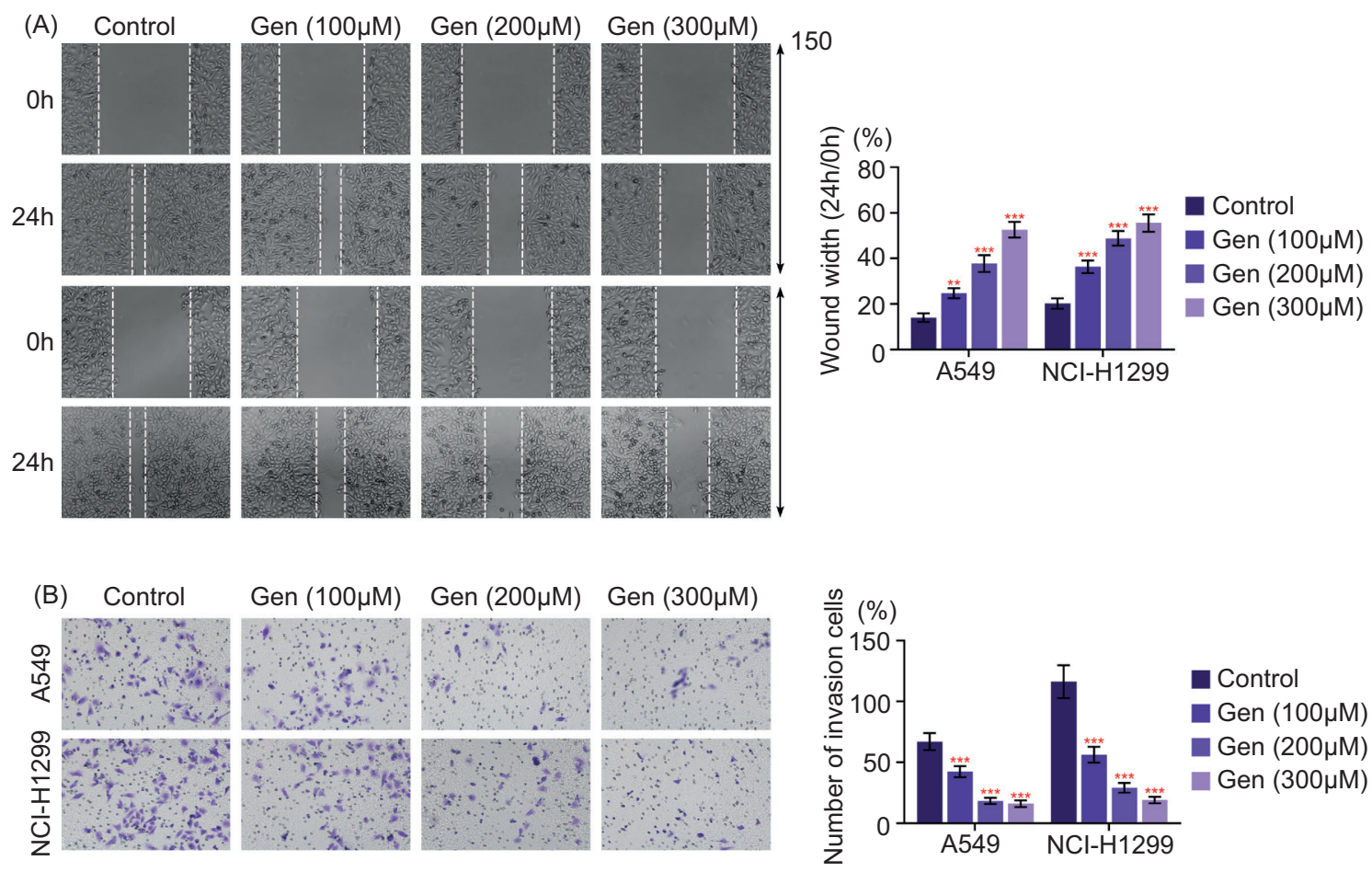

Figure 2. Geniposide repressed NSCLC cell migration and invasion. (A) Incubation with geniposide reduced wound width of A549 and NCl-H1299 cells in a dosage-dependent manner. (B) Incubation with geniposide reduced the number of invasive A549 and $\mathrm{NCl}-\mathrm{H} 1299$ cells in a dosage-dependent manner. ${ }^{* *} P<0.01,{ }^{* * *} P<0.001$. 

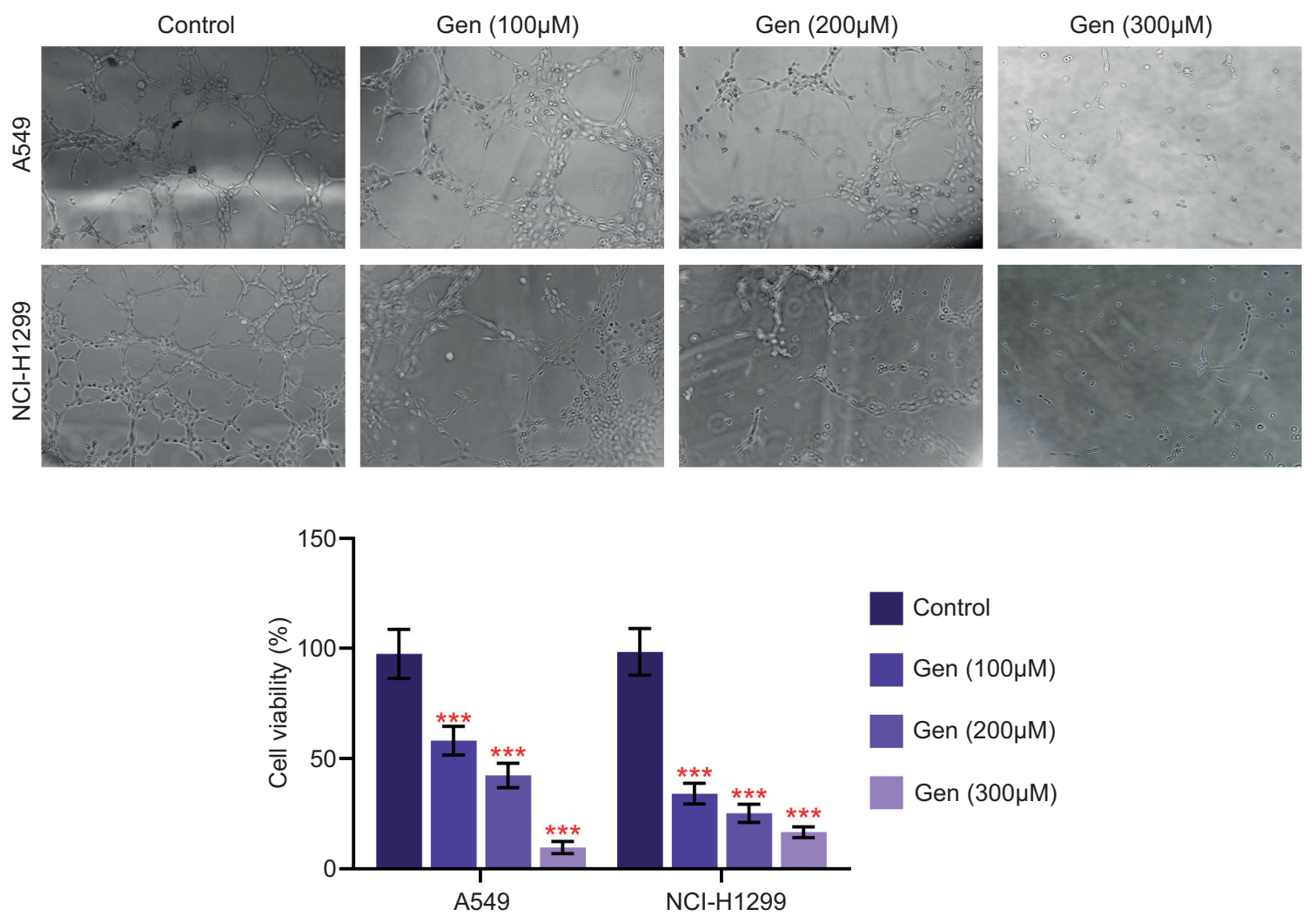

Figure 3. Geniposide repressed the angiogenesis of NSCLC. Incubation with geniposide reduced the number of tubes of HUVECs in a dosage-dependent manner. ${ }^{* * *} P<0.001$.

(A)
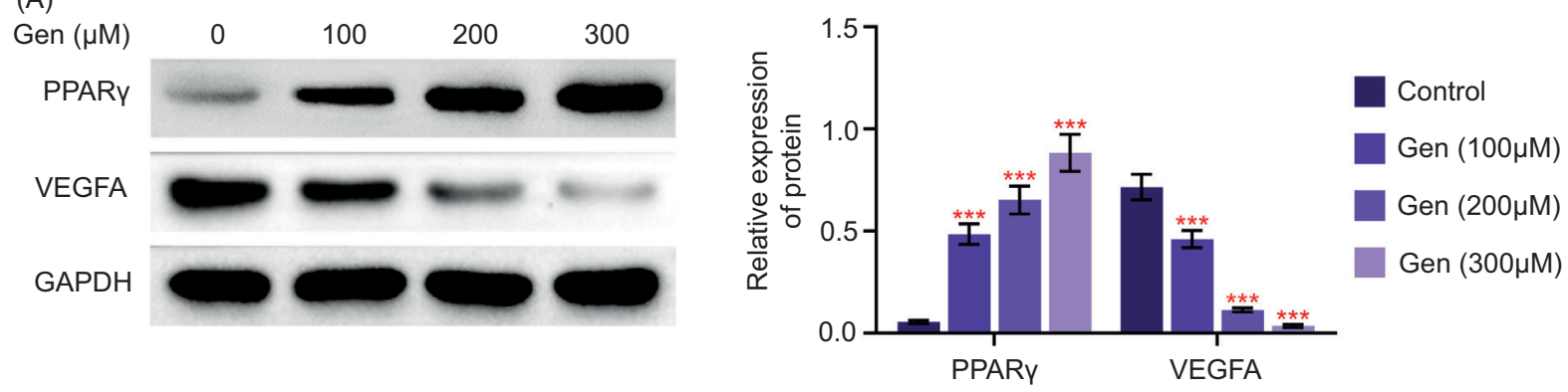

(B)
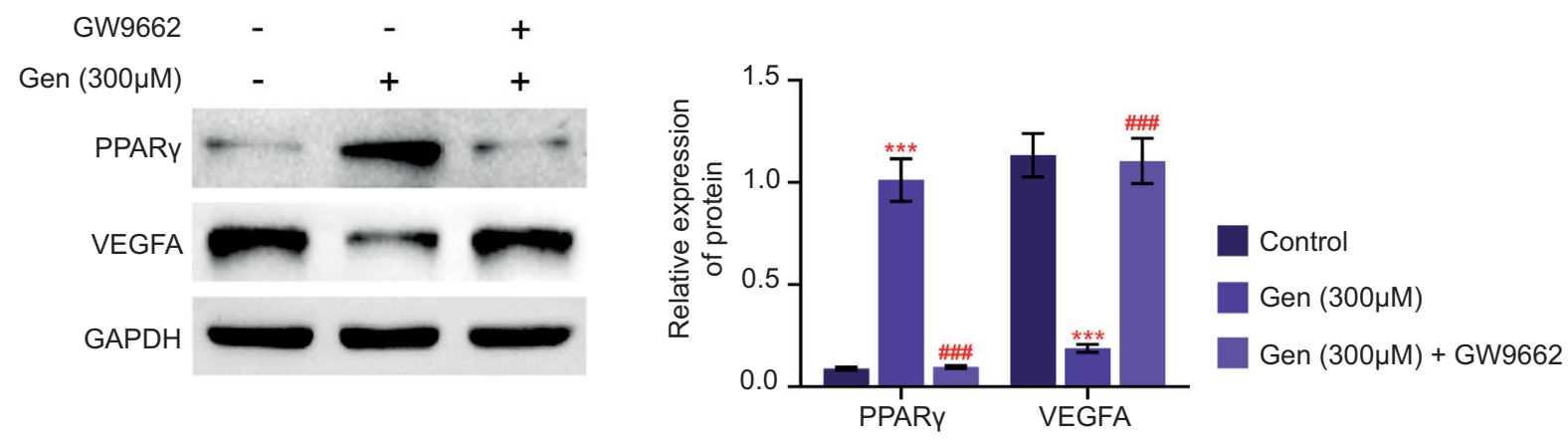

Figure 4. Geniposide reduced expression of VEGF-A through activation of PPAR $\gamma$. (A) Incubation with geniposide reduced the protein expression of VEGF-A and enhanced PPAR $\gamma$ protein expression in A549 and NCI-H1299 cells in a dosage-dependent manner. (B) Incubation with a potent antagonist of PPAR $\gamma$, GW9662, attenuated geniposide-induced up-regulation of PPAR $\gamma$ and down-regulation of VEGF-A in A549 and NCl-H1299 cells. ${ }^{\ldots+\ldots}, \mathrm{P}<0.001$. 


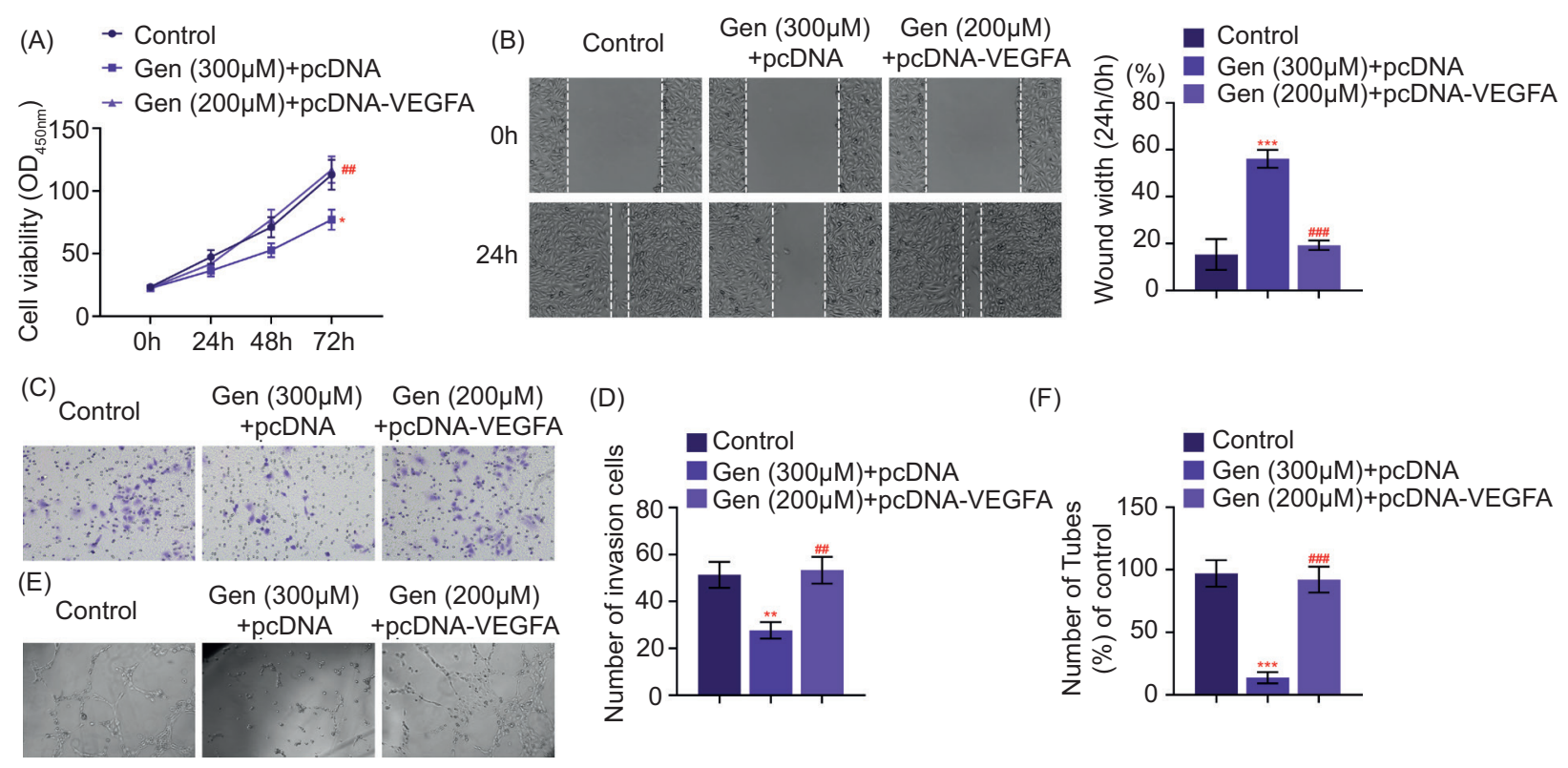

Figure 5. Geniposide repressed NSCLC cell migration and angiogenesis through regulation of VEGF-A. (A) Over-expression of VEGF-A increased the viability of geniposide-induced A549 cell. (B) Over-expression of VEGF-A increased the wound width of geniposide-induced A549 cell. (C) Over-expression of VEGF-A increased the number of invasive cells in geniposide-induced A549 cell. (D) The relative number of invasive cells in geniposide-induced A549 cell with transfection of pcDNA or pcDNAVEGF-A. (E) Over-expression of VEGF-A increased the angiogenesis of geniposide-induced A549 cell. (F) The relative number of tubes in geniposide-induced A549 cell with transfection of pcDNA or pcDNA-VEGF-A. ${ }^{*} P<0.05,{ }^{* *},{ }^{*} P<0.01,{ }^{* * *},{ }^{*} P<0.001$.

promoted by pcDNA-VEGF-A transfection. Overexpression attenuated geniposide-suppressed angiogenesis of A549 cell (Figures 5E and F), demonstrating that geniposide repressed NSCLC cell migration and angiogenesis through regulation of VEGF-A.

\section{Discussion}

This study found that geniposide repressed NSCLC cell proliferation and metastasis. Moreover, the angiogenesis of NSCLC was also repressed by geniposide. Traditional Chinese herbs are widely used as therapies or adjuvant therapies for the treatment of advanced NSCLC (Liu et al., 2014; Zhang et al., 2018). The derivative of geniposide, genipin, has been evidenced to promote the initiation of mitochondrial death cascade through regulation of p38MAPK signaling in NSCLC (Zhang et al., 2015). Moreover, geniposide and genipin exerted cytotoxic effect on cancer cells, suppressing carcinogenesis and metastasis through regulation of cell cycle arrest, cell apoptosis, cell metastasis, invasion, and angiogenesis (Habtemariam and Lentini, 2018). Therefore, geniposide could be regarded as an anticancer agent for the prevention of NSCLC.

Genipin reduced the viability of NSCLC cell, H1299 (Zhang et al., 2015). Results in this study also established that geniposide reduced the viability and suppressed the proliferation of A549 and H1299 cells in a dosagedependent manner. Moreover, genipin induced G2/M arrest and promoted the apoptosis in $\mathrm{H} 1299$ cell through mitochondrial cellular execution pathway (Zhang et al., 2015). Geniposide was also involved in mitochondrial-mediated apoptosis of PC12 cells (Guo et al., 2009). Therefore, geniposide might exert pro-apoptotic effects against NSCLC through mitochondrial apoptotic cascade. Furthermore, NSCLC cell migration and invasion were suppressed by geniposide, suggesting that geniposide exerted anti-proliferative, pro-apoptotic and antiinvasive effects against NSCLC.

Angiogenesis and its related pathological process, metastasis, contribute to the release and activation of distinct factors to promote NSCLC cell proliferation and invasion (D'Amico, 2004). Geniposide has been depicted to suppress the angiogenesis of hepatocellular carcinoma through down-regulation of VEGF (Zhang et al., 2020). Consistently, the results of this study evidenced the anti-angiogenic effect of geniposide against NSCLC, as demonstrated by the reduced number of tubes based on the tube formation assay. Moreover, the protein expression of VEGF, an important mediator in angiogenesis of NSCLC, was also reduced by geniposide. PPAR $\gamma$ functions as a tumor suppressor in NSCLC through regulation of tumor cell proliferation, differentiation, apoptosis, and 
invasion (Han and Roman, 2010). VEGF was reported to be a downstream signaling of PPAR $\gamma$ in the regulation of cell apoptosis, proliferation, invasion, and angiogenesis (Han and Roman, 2010). Depletion of PPAR $\gamma$ promoted the invasiveness of lung cancer cells through activation of VEGF-A-mediated inhibition of cell apoptosis (Tian et al., 2016). Antagonist of PPARY reversed thiazolidinedione-induced up-regulation of VEGF in NSCLC cell (Yoshizaki et al., 2010). Therefore, PPAR $\gamma /$ VEGF signaling was involved in NSCLC cell metastasis and angiogenesis. Geniposide has been reported to up-regulate PPAR $\gamma$ in lipopolysaccharide (LPS)-stimulated human renal tubular epithelial (HK-2) cells and cecal ligation in puncture-induced septic mice to improve renal injury in sepsis (Liu et al., 2020). Moreover, VEGF-A was also predicted as a geniposide-related target (Jin et al., 2021), as geniposide reduced the expression of VEGF-A to attenuate angiogenesis in rheumatoid arthritis (Wang et al., 2021). Here, the protein expression of PPAR $\gamma$ was enhanced by geniposide in NSCLC, and antagonist of PPAR $\gamma$ reversed geniposide-induced up-regulation of PPAR $\gamma$ and down-regulation of VEGF-A, suggesting that geniposide reduced VEGF-A in NSCLC through up-regulation of PPAR $\gamma$. Additionally, functional assays demonstrated that over-expression of VEGF-A attenuated geniposide-induced reduction of cell viability, migration, invasion, and angiogenesis in NSCLC, demonstrating that geniposide exerted anti-invasive and anti-angiogenic effects against NSCLC through PPAR $\gamma /$ VEGF signaling. Geniposide has been regarded as an agonist of glucagon-like peptide-1 receptor $(\mathrm{Li}, \mathrm{Li}, \mathrm{Wu}, \&$ Zhou, 2019), and PPARY is the downstream target of glucagon-like peptide-1 receptor(Onuma et al., 2014). Therefore, geniposide might regulate PPAR $\gamma /$ VEGF signaling by targeting glucagon-like peptide-1 receptor.

\section{Conclusion}

In summary, this study indicated the in vitro antitumor effect of geniposide against NSCLC through inhibition of cell proliferation, migration, invasion, and angiogenesis. The underlying mechanism was associated with up-regulation of PPAR $\gamma$ and down-regulation of VEGF. Taken together, geniposide might function as an inhibitor of angiogenesis in NSCLC. However, its in vivo effect on tumor growth and angiogenesis of NSCLC should be investigated in the future research. The present research established that geniposide could be transformed to genipin by $\beta$-glucosidase in the bowel (Li et al., 2019). Genipin induced NSCLC cell apoptosis (Yang et al., 2013), and suppressed angiogenesis of hepatocellular carcinoma (Hong et al., 2020). Therefore, geniposide might undergo biotransformation into genipin to exert antitumor and anti-angiogenic actions in NSCLC.

\section{Competing Interests}

The authors state that there Were no conflict of interest to disclose.

\section{Author Contributions}

Ming Jiang designed and conducted the experiments. Shiying Zheng analyzed and interpreted the data, prepared the manuscript with contributions from the co-author.

\section{References}

Chen, K., Yu, B. and Liao, J., 2021. LncRNA SOX2OT alleviates mesangial cell proliferation and fibrosis in diabetic nephropathy via Akt/mTOR-mediated autophagy. Molecular Medicine 27: 1-15. https://doi.org/10.1186/s10020-021-00310-6

Cheng, Z., Xu, H., Wang, X. and Liu, Z., 2017. Lactobacillus raises in vitro anticancer effect of geniposide in HSC-3 human oral squamous cell carcinoma cells. Experimental and Therapeutic Medicine 14: 4586-4594. https://doi.org/10.3892/ etm.2017.5105

D'Amico, T.A., 2004. Angiogenesis in non-small cell lung cancer. Seminars in Thoracic and Cardiovascular Surgery 16: 13-18. https://doi.org/10.1053/j.semtcvs.2004.01.003

Elkhider, A., Wang, B., Ouyang, X., Al-Azab, M., Walana, W., Sun, X., Li, H., Tang, Y., Wei, J. and Li, X., 2020. Aquaporin 5 promotes tumor migration and angiogenesis in non-small cell lung cancer cell line H1299. Oncology Letters 19: 1665-1672. https://doi.org/10.3892/ol.2020.11251. Epub 2020 Jan 7

Garon, E.B., Hellmann, M.D., Rizvi, N.A., Carcereny, E., Leighl, N.B., Ahn, M.-J., Eder, J.P., Balmanoukian, A.S., Aggarwal, C., Horn, L., Patnaik, A., Gubens, M., Ramalingam, S.S., Felip, E., Goldman, J.W., Scalzo, C., Jensen, E., Kush, D.A. and Hui, R., 2019. Five-year overall survival for patients with advanced nonsmall-cell lung cancer treated with pembrolizumab: results from the phase I KEYNOTE-001 study. Journal of Clinical Oncology: Official Journal of the American Society of Clinical Oncology 37: 2518-2527. https://doi.org/10.1200/JCO.19.00934

Gridelli, C., Rossi, A., Carbone, D.P., Guarize, J., Karachaliou, N., Mok, T., Petrella, F., Spaggiari, L. and Rosell, R., 2015. Nonsmall-cell lung cancer. Nature Reviews Disease Primers 1: 15009. https://doi.org/10.1038/nrdp.2015.9

Guo, L.-x., Liu, J.-h. and Xia, Z.-n., 2009. Geniposide inhibits $\mathrm{CoCl}_{2}$-induced PC12 cells death via the mitochondrial pathway. Chinese Medical Journal 122(23): 2886-2892. PMID: 2009279

Habtemariam, S. and Lentini, G., 2018. Plant-derived anticancer agents: lessons from the pharmacology of geniposide and its aglycone, genipin. Biomedicines 6: 39. https://doi.org/10.3390/ biomedicines 6020039

Han, S.W. and Roman, J., 2010. Anticancer actions of PPARY ligands: current state and future perspectives in human lung 
cancer. World Journal of Biological Chemistry 1: 31-40. https:// doi.org/10.4331/wjbc.v1.i3.31

Hong, M., Lee, S., Clayton, J., Yake, W. and Li, J., 2020. Genipin suppression of growth and metastasis in hepatocellular carcinoma through blocking activation of STAT-3. Journal of Experimental \& Clinical Cancer Research 39: 1-17. https://doi.org/10.1186/ s13046-020-01654-3

Hu, L., Zhao, J., Liu, Y., Liu, X., Lu, Q., Zeng, Z., Zhu, L., Tong, X. and $\mathrm{Xu}, \mathrm{Q} ., 2020$. Geniposide inhibits proliferation and induces apoptosis of diffuse large B-cell lymphoma cells by inactivating the HCP5/miR-27b-3p/MET axis. International Journal of Medical Sciences 17: 2735-2743. https://doi.org/10.7150/ ijms.51329

Jin, Z., Zhao, H., Luo, Y., Li, J., Pi, J., He, W., Yan, J. and Yang, P., 2021. Geniposide achieved an anti-inflammatory effect through the NF- $\mathrm{kB} / \mathrm{HIF}-1 \alpha$ signaling pathway mediated by VEGFA and HMOX1 genes.

Keedy, V.L. and Sandler, A.B., 2007. Inhibition of angiogenesis in the treatment of non-small cell lung cancer. Cancer Science 98: 1825-1830. https://doi.org/https://doi. org/10.1111/j.1349-7006.2007.00620.x

Kim, Y.H., Nagai, H., Ozasa, H., Sakamori, Y. and Mishima, M., 2013. Therapeutic strategy for non-small-cell lung cancer patients with brain metastases (review). Biomedical Reports 1: 691-696. https://doi.org/10.3892/br.2013.151

Li, N., Li, L., Wu, H. and Zhou, H., 2019. Antioxidative property and molecular mechanisms underlying geniposide-mediated therapeutic effects in diabetes mellitus and cardiovascular disease. Oxidative Medicine and Cellular Longevity 2019: 7480512. https://doi.org/10.1155/2019/7480512

Lichota, A. and Gwozdzinski, K., 2018. Anticancer activity of natural compounds from plant and marine environment. International Journal of Molecular Sciences 19: 3533. https://doi.org/10.3390/ ijms19113533

Liu, J., Guo, L., Yin, F., Zhang, Y., Liu, Z. and Wang, Y., 2013. Geniposide regulates glucose-stimulated insulin secretion possibly through controlling glucose metabolism in INS-1 cells. PloS One 8: e78315. https://doi.org/10.1371/journal.pone.0078315

Liu, J.-H., Yin, F., Guo, L.-X., Deng, X.-H. and Hu, Y.-H., 2009. Neuroprotection of geniposide against hydrogen peroxide-induced PC12 cells injury: involvement of PI3 kinase signal pathway. Acta Pharmacologica Sinica 30: 159-165. https://doi. org/10.1038/aps.2008.25

Liu, J., Zhao, N., Shi, G. and Wang, H., 2020. Geniposide ameliorated sepsis-induced acute kidney injury by activating PPARy. Aging 12: 22744-22758. https://doi.org/10.18632/aging.103902

Liu, Z.-l., Zhu, W.-r., Zhou, W.-c., Ying, H.-f., Zheng, L., Guo, Y.-b., Chen, J.-x. and Shen, X.-h., 2014. Traditional Chinese medicinal herbs combined with epidermal growth factor receptor tyrosine kinase inhibitor for advanced non-small cell lung cancer: a systematic review and meta-analysis. Journal of Integrative Medicine 12: 346-358. https://doi.org/https://doi.org/10.1016/ S2095-4964(14)60034-0

Loong, H.H., Kwan, S.-c.S., Mok, T.S.-k. and Lau, Y.-m., 2018. Therapeutic strategies in EGFR mutant non-small cell lung cancer. Current Treatment Options in Oncology 19: 58. https:// doi.org/10.1007/s11864-018-0570-9

Ma, J. and Ding, Y., 2018. Geniposide suppresses growth, migration and invasion of MKN45 cells by down-regulation of IncRNA HULC. Experimental and Molecular Pathology 105: 252-259. https://doi.org/https://doi.org/10.1016/j.yexmp.2018.08.011

Malapelle, U. and Rossi, A., 2019. Emerging angiogenesis inhibitors for non-small cell lung cancer. Expert Opinion on Emerging Drugs 24: 71-81. https://doi.org/10.1080/14728214.2019. 1619696

Onuma, H., Inukai, K., Kitahara, A., Moriya, R., Nishida, S., Tanaka, T., Katsuta, H., Takahashi, K., Sumitani, Y. and Hosaka, T., 2014. The glucagon-like peptide 1 receptor agonist enhances intrinsic peroxisome proliferator-activated receptor $\gamma$ activity in endothelial cells. Biochemical and Biophysical Research Communications 451: 339-344. https://doi.org/10.1016/j. bbrc.2014.07.136

Thawani, R., Fakhoury, K. and Becker, K.D., 2020. Cause of mortality in patients with lung cancer and brain metastasis. Journal of Clinical Oncology 38: e21743. https://doi.org/10.1200/ JCO.2020.38.15_suppl.e21743

Tian, J., Hu, L., Li, X., Geng, J., Dai, M. and Bai, X., 2016. MicroRNA-130b promotes lung cancer progression via PPAR $\gamma /$ VEGF-A/BCL-2-mediated suppression of apoptosis. Journal of Experimental \& Clinical Cancer Research 35: 105-105. https:// doi.org/10.1186/s13046-016-0382-3

Wang, Y., Wu, H., Deng, R., Dai, X.j., Bu, Y.h., Sun, M.h., Zhang, H., Wang, M.d. and Wang, R.h., 2021. Geniposide downregulates the VEGF/SphK1/S1P pathway and alleviates angiogenesis in rheumatoid arthritis in vivo and in vitro. Phytotherapy Research 35(8): 4347-4362. https://doi.org/10.1002/ptr.7130

Yang, X., Lei, P., Huang, Y., Zhang, Z. and Zhang, Y., 2016. MicroRNA-133b inhibits the migration and invasion of non small cell lung cancer cells via targeting FSCN1. Oncology Letters 12: 3619-3625. https://doi.org/10.3892/ol.2016.5044.

Yang, X., Yao, J., Luo, Y., Han, Y., Wang, Z. and Du, L., 2013. P38 MAP kinase mediates apoptosis after genipin treatment in nonsmall-cell lung cancer H1299 cells via a mitochondrial apoptotic cascade. Journal of Pharmacological Sciences 121: 272-281. https://doi.org/10.1254/jphs.12234fp

Yoshizaki, T., Motomura, W., Tanno, S., Kumei, S., Yoshizaki, Y., Tanno, S. and Okumura, T., 2010. Thiazolidinediones enhance vascular endothelial growth factor expression and induce cell growth inhibition in non-small-cell lung cancer cells. Journal of Experimental \& Clinical Cancer Research 29: 22. https://doi. org/10.1186/1756-9966-29-22

Yu, X., Wang, Y., Tao, S. and Sun, S., 2020. Geniposide plays anti-tumor effects by down-regulation of microRNA-224 in HepG2 and Huh7 cell lines. Experimental and Molecular Pathology 112: 104349. https://doi.org/10.1016/j.yexmp.2019.104349

Zhang, X.-W., Liu, W., Jiang, H.-L. and Mao, B., 2018. Chinese herbal medicine for advanced non-small-cell lung cancer: a systematic review and meta-analysis. American Journal of Chinese Medicine 46: 923-952. https://doi.org/10.1142/ S0192415X185004.90 
Zhang, C., Wang, N., Tan, H.-Y., Guo, W., Chen, F., Zhong, Z., Man, K., Tsao, S.W., Lao, L. and Feng, Y., 2020. Direct inhibition of the TLR4/MyD88 pathway by geniposide suppresses HIf 1N independent VEGF expression and angiogenesis in hepatocellular carcinoma. British Journal of Pharmacology 177: 3240-3257. https://doi.org/10.1111/bph.15046
Zhang, B., Wu, T., Wang, Z., Zhang, Y., Wang, J., Yang, B., Zhao, Y., Rao, Z. and Gao, J., 2015. p38MAPK activation mediates tumor necrosis Factor- $\alpha$-induced apoptosis in glioma cells. Molecular Medicine Reports 11: 3101-3107. https://doi. org $/ 10.3892 / \mathrm{mmr} .2014 .3002$ 